\title{
Comparison on the status of vitamin $A$ in 6- to 13- year-old children between 2002 and 2012 in China
}

Chun Yang ${ }^{1}$, Jing Chen ${ }^{1}$, Ning Guo ${ }^{1,2}$, Zhen Liu', Chunfeng Yun ${ }^{1}$, Yajie Li ${ }^{1}$, Jianhua Piao ${ }^{1}$ and Xiaoguang Yang ${ }^{1 *}$

\begin{abstract}
Background: Vitamin A deficiency is recognized as a major public-health nutrition issue in the developing countries. Limited hospital sources and sample sizes are available in most of the existing studies associated with healthy school-age children. The aim of this study was to compare vitamin A status of 6- to 13-year-old healthy children in China between 2002 and 2012.
\end{abstract}

Methods: According to China National Nutrition and Health Survey 2002 (CHNNS2002) and CHNNS2010-2013, we choose 6- to 13-year-old children as the research object. We measure the serum retinol concentrations of the children using high performance liquid chromatography (HPLC). The children were divided into two groups: 6- to 9-year-old and 10- to 13-year-old. The areas were divided into urban and rural area.

Results: Total number of the children (6- to 13-year old) was 8170 in 2002 survey, and it was 6016 in 2012 survey. In 2012, the vitamin A level of the children was higher than that in $2002(t=39.26, p=0.000)$. The level of vitamin A in 10- to 13-year-old group was higher than that in 6- to 9-year-old group across areas and genders between 2002 and 2012. There was no difference on the incidence of vitamin A deficiency in all the children between 2002 and 2012, but in 2012 the incidence of vitamin A deficiency in the urban children was higher than that in $2002\left(x^{2}=45.456, p=0.000\right)$. The incidence of vitamin A deficiency in 10- to 13-year-old group was lower than that in 10- to 13-year-old group across areas and genders between 2002 and 2012. In 2012, the incidence of marginal vitamin A deficiency in the children was lower than that in $2002\left(x^{2}=861.604, p=0.000\right)$. Similar phenomena were also found in across area groups. The incidence of marginal vitamin A deficiency in 10- to 13-year-old group was lower than that in 6to 9-year-old group across areas and genders between 2002 and 2012. There was no difference in vitamin A status of the children across the area, gender and age groups between 2002 and 2012.

Conclusion: Vitamin A nutritional status of the children in 2012 has been significantly improved compared with that in 2002. However, vitamin A deficiency was still a moderate public health problem in Chinese children, especially in younger school-age children. Consequently, controlling the incidence of vitamin a deficiency is imperative for promoting Chinese children's health.

Keywords: Vitamin A status, Children, China

\footnotetext{
* Correspondence: xgyangcdc@vip.sina.com

${ }^{1}$ Key Laboratory of Trace Element Nutrition, National Health and Family Planning Commission of the people's Republic of China, Department of Trace Element Nutrition, National Institute for Nutrition and Health, Chinese Center for Disease Control and Prevention, Room 236, Nanwei Road No.29, Xicheng District, Beijing 100050, China

Full list of author information is available at the end of the article
} 


\section{Background}

Vitamin A is an essential nutrient needed in small amounts for the normal functioning of the visual system, and maintenance of cell function for growth, epithelial integrity, red blood cell production, immunity and reproduction [1]. The World Health Organization (WHO) defines vitamin A deficiency (VAD) as tissue concentrations of vitamin A low enough to have adverse health consequences, even if there is no evidence of clinical deficiency [2]. Serum retinol concentration is a reliable indicator of an individual's vitamin A status [3].

VAD has been recognized as a major public-health nutrition issue in developing countries [1]. According to WHO, serum retinol concentrations are classified as $\geq 1.05 \mu \mathrm{mol} / \mathrm{L}$ for normal, $0.70-1.05 \mu \mathrm{mol} / \mathrm{L}$ for marginal, and $<0.70 \mu \mathrm{mol} / \mathrm{l}$ for deficient, respectively [4]. The degree of severity of VAD is defined as mild, moderate and severe: the prevalence of marginal or deficient serum/plasma concentrations is $2-10 \%$, if prevalence is $10-20 \%$ and if prevalence is over $20 \%$ [1]. Previous reports have made an effort to identify VAD in the children at the age of 5 to 15 years in Southeast Asia. It is suggested that $23 \%$ of the population ( 83 million) in this age range had lower serum retinol concentrations than $0.7 \mathrm{mmol} / \mathrm{L}$ [5], so VAD is considered as a serious public health problem in Southeast Asia. There are some risk factors associated with VAD, such as gender, age, weight, socio-demographic characteristics, socio-economic status of the family, nutritional habits of the children, recent infections, and maternal education and so on [6-8]. However, little data are available on the status of VAD of 6- to 13-year-old children in China. Therefore, there is an urgent need to illustrate the prevalence of VAD in healthy school-age children in China.

This study was designed to compare vitamin A status of 6- to 13-year-old children between 2002 with 2012 in China, and to provide information regarding whether the VAD constitute a public health problem. The findings from the current study will contribute to provide means to combat VAD.

\section{Methods}

\section{Study participants}

The survey was conducted from August to December in 2002 with a well-designed stratified multistage cluster sampling method, and covered all 31 provinces, autonomous regions, and municipalities directly under the central government throughout China (except Taiwan, Hong Kong, and Macao). The country was divided into 6 strata (large cities, small to medium cities, class 1 rural areas, class 2 rural areas, class 3 rural areas, and class 4 rural areas) based on geographic characteristics, economy and social development, according to the China National Bureau of Statistics and China Ministry of Health Statistics.
The first stage of sampling involved the random selection of 22 districts (urban) or counties (rural) from each of the 6 strata. The second stage involved the random selection of 3 neighborhoods (urban) or townships (rural) from each of the selected districts/counties. From each of the neighborhoods or townships, 2 residential committees (urban) or villages (rural) were randomly selected; 90 households were randomly sampled from each village 6 [9]. A total of 132 monitoring sites were included in the analysis, and 6 children (6- to 13- year old) were randomly selected at each site according to age and sex.

The survey in 2012 from nationally representative cross-sectional study was conducted by Chinese Center for Disease Control and Prevention to assess the health and nutrition of Chinese civilians. It covered all 31 provinces, autonomous regions, and municipalities directly under the central government throughout China (except Taiwan, Hong Kong, and Macao). A stratified multistage probability sampling design was used for the selection of participants. The country was divided into four strata (large cities, small to medium cities, general rural areas and poor rural areas) by their economic characteristics and social development. A total of 150 monitoring sites were included in the analysis, and 5 children (6- to 13year old) were randomly selected at each site according to age and sex.

Under the leadership of the Disease Prevention and Control Bureau of Chinese Ministry of Health, National institute of nutrition and health, Chinese center for disease control and prevention was responsible for the implementation of the national level training work (grade 1 ), which for the provinces (autonomous regions/municipalities directly under the central government throughout China) project personnel the spot investigation and monitoring technology backbone technical training method and laboratory operation. Provincial training plan by the project team though national organizations at the provincial level training (grade 1), which to the provincial (autonomous regions/municipalities directly under the central government throughout China) all professional and technical training for staff involved in monitoring, training qualified rear can participate in the monitoring study.

The study was divided into two groups by age: 6- to 9year-old and 10- to13-year-old. In 2002, we considered large cities, small to medium cities as urban areas, and class 1 rural area, class 2 rural areas, class 3 rural areas, and class 4 rural areas as rural areas. In 2012, we considered large cities, small to medium cities as urban areas, and general rural areas and poor rural areas as rural areas.

Ethics approval was obtained from the Ethics Committee of China Centre for Disease Control. All participants gave informed consent. 


\section{Blood samples and biochemical measurement}

Blood samples (about $4 \mathrm{~mL}$ ) of each subject were collected by venipuncture from the antecubital vein before breakfast. The blood was centrifuged at $1500 \times \mathrm{g}$ for $10 \mathrm{~min}$ at $4{ }^{\circ} \mathrm{C}$ and then separated immediately. The centrifuged serum samples at least $500 \mu \mathrm{L}$ were transported to the laboratory away from light and stored at $-80{ }^{\circ} \mathrm{C}$. The concentration of serum retinol was determined by using highperformance liquid chromatographic apparatus (HPLC) (Waters 2487UV detector USA) [10]. Retinol was extracted with hexane after deproteinization with ethanol containing retinyl acetate as the internal standard and evaporated to dryness with nitrogen gas. The residual materials were dissolved in $0.2 \mathrm{~mL}$ ethanol. The mobile phase which was a methanol: $\mathrm{DH} 2 \mathrm{O}$ mixture (96: 4). A portion $(10 \mu \mathrm{L})$ of the sample was injected into a column (3.9.150 mm; Symmetry Shield RPl8 Waters Breeze, Milford, MA, USA) installed with a HPLC (Waters 1525 Binary HPLC Pump, Waters Breeze). All procedures were performed in a dark room to protect the serum from light. The concentration of retinol was determined with a spectrophotometer (Waters 2487 Dual 1 Absorbance Detector, Waters Breeze) at $325 \mathrm{~nm}$. Duplicate analyses were performed on one-tenth of the samples and the estimated variability was $0.02 \mu \mathrm{mol} / \mathrm{L}$. The experienced examiners measured all biochemical indices.

\section{Statistical methods}

SAS version 9.2 (SAS Institute, Inc, Cary, North Carolina) was used for all analyses. Continuous variables were presented as mean $\pm S D$ while categorical variables were presented as percentage rate. Independent-Samples $T$ test were used to compare continuous variables data and the percentage rates were assessed with chi-square test. A value of $p<0.05$ was considered statistically significant.

\section{Results}

In 2002 survey, total number of the children (6- to 13year-old) was 8170 . The numbers of boys and girls were 4038 and 4132, respectively. In 2012 survey, total number of the children (6- to 13-year-old) was 6016. The numbers of boys and girls were 3059 and 2957, respectively. The specific numbers of children in our study were shown in Table 1.

In 2012, vitamin A level of all the children was higher than that in $2002(t=39.26, p=0.000)$. Similar phenomena were also found in different area groups. The level of vitamin A was no difference between boys and girls across the area and age groups. The level of vitamin $\mathrm{A}$ in 10- to 13-year-old group was higher than that in 6- to 9-year-old group across areas and genders between 2002 and 2012 (Table 2). There was no difference on the incidence of vitamin A deficiency in all the children between 2002 and 2012, but in 2012 the
Table 1 The number of 6-13 year old children at 2002 and 2012

\begin{tabular}{|c|c|c|c|c|c|c|c|c|}
\hline \multirow{3}{*}{$\begin{array}{l}\text { Age group } \\
\text { (year) }\end{array}$} & \multicolumn{4}{|l|}{2002} & \multicolumn{4}{|l|}{2012} \\
\hline & \multicolumn{2}{|c|}{ Urban } & \multicolumn{2}{|l|}{ Rural } & \multicolumn{2}{|c|}{ Urban } & \multicolumn{2}{|l|}{ Rural } \\
\hline & Boys & Girls & Boys & Girls & Boys & Girls & Boys & Girls \\
\hline $6-9$ & 474 & 479 & 1872 & 1796 & 714 & 691 & 974 & 959 \\
\hline $10-13$ & 341 & 353 & 1445 & 1410 & 511 & 548 & 794 & 759 \\
\hline \multirow[t]{2}{*}{ Total } & 1647 & & \multirow{2}{*}{\multicolumn{2}{|c|}{6523}} & \multicolumn{2}{|l|}{2530} & \multicolumn{2}{|l|}{3486} \\
\hline & \multicolumn{2}{|l|}{8170} & & & 6016 & & & \\
\hline
\end{tabular}

incidence of vitamin A deficiency in the urban children was higher than that in $2002\left(x^{2}=45.456, p=0.000\right)$. There was also no difference on the VAD between boys and girls across area and age. The VAD of in 10- to 13year-old group was lower than that in 6- to 9-year-old group across area and gender between 2002 and 2012 (Table 3).

In 2012, the incidence of marginal VAD in the children was lower than that in $2002\left(x^{2}=861.604, p=\right.$ 0.000). Similar phenomena were also found in across area groups. The incidence of marginal VAD in 10- to 13-year-old group was lower than that in 6- to 9-yearold group across areas and genders between 2002 and 2012. There was no difference in vitamin A status of the children across the area, gender and age groups between 2002 and 2012 (Table 4).

\section{Discussion}

The main finding of this study indicate that the levels of vitamin A increased with age increase, and VAD and marginal VAD decreased with age increase of the children in China in 2002 and 2012. Our results are consistent with those observed in previous studies $[6,11,12]$, suggested greater vulnerability of younger children than older one. It is possibly due to physical growth, adverse effects of virus and bacterial infections, as well as parasitic infections common in younger age group. In addition, 10- to 13-year-old Chinese children was facing the period from primary to junior high school. The majority of parents pay more attention to children's nutrition, and the greater diversification of dietary pattern observed in those children. It maybe have other reason such as use of one single cut-off point for all age groups, not consideration potentially physiologically lower vitamin A levels in younger children [13]. No significant difference on vitamin A status between boys and girls in this study were consistent with other studies $[6,12]$. The reason could be that the Chinese family planning policy that only one child per family, so no matter boys and girls to parents with the same attitude about child's growth. 
Table 2 Comparison of vitamin A levels in children between 2002 and 2012

\begin{tabular}{|c|c|c|c|c|c|c|c|c|c|c|c|c|}
\hline \multirow{3}{*}{$\begin{array}{l}\text { Age group } \\
\text { (year) }\end{array}$} & \multicolumn{6}{|l|}{2002} & \multicolumn{6}{|l|}{2012} \\
\hline & \multicolumn{3}{|l|}{ Urban } & \multicolumn{3}{|l|}{ Rural } & \multicolumn{3}{|l|}{ Urban } & \multicolumn{3}{|l|}{ Rural } \\
\hline & Boys & Girls & Total & Boys & Girls & Total & Boys & Girls & Total & Boys & Girls & Total \\
\hline $6-9$ & $0.11 \pm 0.03$ & $0.11 \pm 0.03$ & $0.11 \pm 0.03$ & $0.09 \pm 0.02$ & $0.09 \pm 0.03$ & $0.09 \pm 0.02$ & $0.14 \pm 0.02$ & $0.14 \pm 0.03$ & $0.14 \pm 0.03$ & $0.12 \pm 0.02$ & $0.13 \pm 0.03$ & $0.13 \pm 0.03$ \\
\hline 10-13 & $0.13 \pm 0.03$ & $0.13 \pm 0.04$ & $0.13 \pm 0.04^{a}$ & $0.11 \pm 0.03$ & $0.11 \pm 0.03$ & $0.11 \pm 0.03^{b}$ & $0.15 \pm 0.04$ & $0.15 \pm 0.03$ & $0.15 \pm 0.03^{c}$ & $0.14 \pm 0.03$ & $0.14 \pm 0.03$ & $0.14 \pm 0.04^{d}$ \\
\hline \multirow[t]{2}{*}{ Total } & \multicolumn{3}{|l|}{$0.12 \pm 0.03$} & \multicolumn{3}{|l|}{$0.10 \pm 0.03$} & \multicolumn{3}{|l|}{$0.14 \pm 0.03^{e}$} & \multicolumn{3}{|l|}{$0.13 \pm 0.03^{f}$} \\
\hline & \multicolumn{6}{|l|}{$0.11 \pm 0.03$} & \multicolumn{6}{|l|}{$0.14 \pm 0.03^{9}$} \\
\hline
\end{tabular}

In urban areas at 2002, 10-13 age group compared to 6-9 age group, $\mathrm{t}=6.26 p=0.000$ statistically significant

$\mathrm{b}$ In rural areas at 2002, 10-13 age group compared to6-9 age group, $\mathrm{t}=12.06 p=0.000$ statistically significant

In urban areas at 2012, 10-13 age group compared to 6-9 age group, $\mathrm{t}=2.55 p=0.0107$ statistically significant

In rural areas at 2012, 10-13 age group compared to 6-9 age group, $\mathrm{t}=4.33 p=0.000$ statistically significant

eln urban areas at 2012 compared to urban in 2002, $\mathrm{t}=13.21 p=0.000$ statistically significant

fIn rural areas at 2012compared to rural in 2002, $\mathrm{t}=27.96 p=0.000$ statistically significant

${ }^{9}$ compared to $2002, \mathrm{t}=39.26 p=0.000$ statistically significant 
Table 3 Comparison of vitamin A deficiency of children between 2002 and 2012(\%/n)

\begin{tabular}{|c|c|c|c|c|c|c|c|c|c|c|c|c|}
\hline \multirow{3}{*}{$\begin{array}{l}\text { Age group } \\
\text { (year) }\end{array}$} & \multicolumn{6}{|l|}{2002} & \multicolumn{6}{|l|}{2012} \\
\hline & \multicolumn{3}{|l|}{ Urban } & \multicolumn{3}{|l|}{ Rural } & \multicolumn{3}{|l|}{ Urban } & \multicolumn{3}{|l|}{ Rural } \\
\hline & Boys & Girls & Total & Boys & Girls & Total & Boys & Girls & Total & Boys & Girls & Total \\
\hline $6-9$ & $5.06 / 24$ & $4.38 / 21$ & $4.72 / 45$ & $13.35 / 250$ & $12.14 / 218$ & $12.76 / 468$ & $11.90 / 85$ & $9.41 / 65$ & $10.68 / 150$ & $9.45 / 92$ & $8.24 / 79$ & $8.85 / 171$ \\
\hline $10-13$ & $2.64 / 9$ & $2.55 / 9$ & $2.59 / 18^{\mathrm{a}}$ & $6.64 / 96$ & $7.38 / 104$ & $7.00 / 200^{b}$ & $8.61 / 44$ & $7.66 / 42$ & $7.64 / 86^{c}$ & $6.80 / 54$ & $4.08 / 31$ & $5.47 / 85^{d}$ \\
\hline \multirow[t]{2}{*}{ Total } & \multicolumn{3}{|l|}{$3.83 / 63$} & \multicolumn{3}{|l|}{$10.24 / 668$} & \multicolumn{3}{|c|}{$9.33 / 236^{\mathrm{e}}$} & \multicolumn{3}{|l|}{$7.34 / 256^{f}$} \\
\hline & \multicolumn{3}{|l|}{$8.95 / 731$} & & & & \multicolumn{3}{|c|}{$8.18 / 492^{g}$} & & & \\
\hline
\end{tabular}

${ }^{a}$ In urban areas at 2002, 10-13 age group compared to 6-9 age group, $x^{2}=4.998 p=0.025$ statistically significant

bIn rural areas at 2002, 10-13 age group compared to6-9 age group, $x^{2}=5.765 p=0.000$ statistically significant

'In urban areas at 2012, 10-13 age group compared to 6-9 age group, $x^{2}=6.789 p=0.009$ statistically significant

In rural areas at 2012, 10-13 age group compared to 6-9 age group, $x^{2}=14.791 p=0.000$ statistically significant

${ }^{\mathrm{e}}$ In urban areas at 2012 compared to urban in $2002, x^{2}=45.456 p=0.000$ statistically significant

fIn rural areas at 2012compared to rural in 2002, $x^{2}=33.257 p=0.000$ statistically significant

${ }^{9}$ compared to $2002, x^{2}=2.602 p=0.107$ no statistically significant

During the past decades of rapid socio-economic development in China, urbanization and modernization was great success in improvement of children nutritional status, which resulted in reduced mortality rates, underweight and stunting of children [14]. Our study compared the level of vitamin A of children between 2002 and 2012. The level of vitamin A in 2012 was higher than that in 2002. The reason may be attribute to the promotion of successful agricultural and economic reforms during the past ten years in China. The sustainable food security system kept stable food pricing and food provisions for the nation's 1.3 billion population, which was able to get the food items essential for health. Increased the income of average family enables parents to provide a variety of food for their children [15]. A significant increase in dietary diversity was observed, and more people consumed food from a larger number of food groups [16]. The intake of vegetables, fruits, cakes, and milk and other animal products like pork, poultry and eggs are increasing [17]. Those dietary food are rich in vitamin A increased the levels of vitamin A of the children at 2012.

There was no significant difference on VAD of the children between 2002 and 2012, but the VAD of the urban children in 2012was higher than that in 2002. A meta-analysis indicated that the prevalence of overweight/obesity has increased significantly among both boys and girls in China from 1981 to 2010. Similar tendency were found from infancy to adolescence in both urban and rural areas. However, the prevalence of overweight/obesity in urban areas was higher than that in rural areas [18]. Several studies found overweight and obese adults and children have lower blood concentrations of vitamins such as vitamin A and minerals compared with those in normal-weight subjects, and $\beta$ carotene,as vitamin A precursors,was also declined in overweight and obese adults and children [19-22]. The physiology of micronutrient metabolism was altered in obese and overweight individuals, with greater fat mass resulting in increased sequestering of lipophilic vitamins in adipose tissue [23]. In our future study we should pay more attention to the status of vitamin A in Chinese urban children, especially in overweight and obese children.

In recent years, cases of clinical VAD were considered to represent only the tip of the iceberg, while number of VAD in children was on the decline,with the existence of much larger amount of populations in less advanced (marginal) stages of deficiency, this fact that may also lead to increasing morbidity and mortality among children, newborn babies, women of reproductive age, puerperium and nursing mothers, who traditionally considered to be at risk [12]. Though the prevalence of marginal VAD declined in 2012 (22\%), it was still a moderate public health problem.

The limitation of the present study is that: our study was lack of socioeconomic status, dietary intake, anthropometric data as well as other general information of Chinese children and also our study was not consider about the effect of CRP on the vitamin A status of Chinese school-age children. However, our study was first report that the vitamin A status of Chinese schoolage children at national level. In future studies, we will think about more factors which affect the vitamin A status of Chinese school-age children.

\section{Conclusions}

In summary, compared to 2002, the vitamin A status of children was improved in 2012. VAD was still a moderate public health problem in Chinese children. Lower age and in urban of children was easy to occurrence vitamin A deficiency, so in future we should pay more attention to lower age and in urban of children as to prevent vitamin A deficiency occurrence and promote Chinese children's health. 
Table 4 Comparison of marginal vitamin A deficiency in children between 2002 and 2012(\%/n)

\begin{tabular}{|c|c|c|c|c|c|c|c|c|c|c|c|c|}
\hline \multirow{3}{*}{$\begin{array}{l}\text { Age group } \\
\text { (year) }\end{array}$} & \multicolumn{6}{|l|}{2002} & \multicolumn{6}{|l|}{2012} \\
\hline & \multicolumn{3}{|l|}{ Urban } & \multicolumn{3}{|l|}{ Rural } & \multicolumn{3}{|l|}{ Urban } & \multicolumn{3}{|l|}{ Rural } \\
\hline & Boys & Girls & Total & Boys & Girls & Total & Boys & Girls & Total & Boys & Girls & Total \\
\hline $6-9$ & $32.27 / 153$ & $32.78 / 157$ & $32.53 / 310$ & $51.55 / 965$ & $50.01 / 899$ & $50.80 / 1864$ & $20.72 / 148$ & $23.30 / 161$ & 21.99/309 & $23.82 / 232$ & $25.86 / 248$ & $24.83 / 480$ \\
\hline 10-13 & 26.39/90 & $25.78 / 91$ & $26.08 / 181^{a}$ & $44.01 / 636$ & $42.91 / 605$ & $43.47 / 1241^{b}$ & $22.11 / 113$ & $16.06 / 88$ & $17.87 / 201^{c}$ & $20.03 / 159$ & $22.66 / 172$ & $21.31 / 331^{d}$ \\
\hline \multirow[t]{2}{*}{ Total } & \multicolumn{3}{|l|}{$29.81 / 491$} & \multicolumn{3}{|l|}{$49.69 / 3241$} & \multicolumn{3}{|l|}{$19.80 / 501^{e}$} & \multicolumn{3}{|l|}{$23.26 / 811^{f}$} \\
\hline & \multicolumn{6}{|l|}{$45.68 / 3732$} & \multicolumn{3}{|l|}{$21.82 / 1312^{\mathrm{g}}$} & & & \\
\hline
\end{tabular}

\footnotetext{
In urban areas at 2002, 10-13 age group compared to 6-9 age group, $x^{2}=7.980 p=0.005$ statistically significant

b/n rural areas at 2002, 10-13 age group compared to6-9 age group, $x^{2}=34.648 p=0.000$ statistically significant

In urban areas at 2012, 10-13 age group compared to 6-9 age group, $x^{2}=94.831 p=0.000$ statistically significant

In urban areas at $2012,10-13$ age group compared to $6-9$ age group, $x^{2}=94.831 p=0.000$ statistically significant
In rural areas at $2012,10-13$ age group compared to 6-9 age group, $x^{2}=5.971 p=0.015$ statistically significant

In urban areas at 2012 compared to urban in $2002, x^{2}=55.192 p=0.000$ statistically significant

fIn rural areas at 2012 compared to rural in $2002, x^{2}=657.579 p=0.000$ statistically significant
}

${ }^{9}$ compared to $2002, x^{2}=861.604 p=0.000$ statistically significant 


\section{Competing interests}

The authors declare that they have no competing interests.

\section{Authors' contributions}

$X Y$ designed research; JP and JC conducted research; NG and ZL provided essential reagents and materials; $C Y$ and $Y L$ analyzed data; and $C Y$ wrote the paper. XY had primary responsibility for final content. All authors read and approved the final manuscript

\section{Acknowledgements}

This research was supported by Special Fund for Health-scientific Research in the Public Interest (No. 20120212) from national health and family planning commission of the People's Republic of China. We thank all the participants in our study and the staffs work for China National Nutrition and Health Survey 2002 (CHNNS2002) and China National Nutrition and Health Survey 2010-2013 (CHNNS2010-2013). None of the authors had any personal or financial conflicts of interest.

\section{Author details}

${ }^{1}$ Key Laboratory of Trace Element Nutrition, National Health and Family Planning Commission of the people's Republic of China, Department of Trace Element Nutrition, National Institute for Nutrition and Health, Chinese Center for Disease Control and Prevention, Room 236, Nanwei Road No.29, Xicheng District, Beijing 100050, China. ${ }^{2}$ Jinnan District Center for Disease Control and Prevention of Tianjin, Tianjin 300350, China.

Received: 18 July 2015 Accepted: 28 April 2016

Published online: 04 May 2016

\section{References}

1. Organization WH. Global prevalence of vitamin A deficiency in populations at risk 1995-2005: WHO global database on vitamin A deficiency. World Health Organization. 2009;2009:55

2. World Health Organization FaAOotUN. Vitamin and mineral requirements in human nutrition: vitamin A. 2nd ed. Geneva: World Health Organization; 2004. p. 17-37.

3. Hennekens $\mathrm{CH}$, Mayrent SL, Willett W. Vitamin A, carotenoids, and retinoids. Cancer. 1986;58:1837-41.

4. Control of vitamin A deficiency and xerophthalmia. World Health Organ Tech Rep Ser. 1982;672:1-70. PMID:6803444.

5. Singh V, West Jr KP. Vitamin A deficiency and xerophthalmia among schoolaged children in Southeastern Asia. Eur J Clin Nutr. 2004;58:1342-9.

6. Vuralli D, Tumer L, Hasanoglu A, Biberoglu G, Pasaoglu H. Vitamin A status and factors associated in healthy school-age children. Clin Nutr. 2014;33: 509-12.

7. de Cassia Ribeiro-Silva R, Nunes IL, Assis AM. Prevalence and factors associated with vitamin A deficiency in children and adolescents. J Pediatr (Rio J). 2014;90:486-92

8. Tornaritis MJ, Philippou E, Hadjigeorgiou C, Kourides YA, Panayi A, Savva SC. A study of the dietary intake of Cypriot children and adolescents aged 6-18 years and the association of mother's educational status and children's weight status on adherence to nutritional recommendations. BMC Public Health. 2014;14:13.

9. Wu Y, Huxley R, Li L, Anna V, Xie G, Yao C, Woodward M, Li X, Chalmers J, Gao R, et al. Prevalence, awareness, treatment, and control of hypertension in China: data from the China National Nutrition and Health Survey 2002. Circulation. 2008;118:2679-86

10. Hariharan M, VanNoord T, Greden JF. A high-performance liquidchromatographic method for routine simultaneous determination of nicotine and cotinine in plasma. Clin Chem. 1988:34:724-9.

11. Breidenassel C, Valtuena J, Gonzalez-Gross M, Benser J, Spinneker A, Moreno LA, de Henauw S, Widhalm K, Molnar D, Maiani G, et al. Antioxidant vitamin status (A, E, C, and beta-carotene) in European adolescents - the HELENA Study. Int J Vitam Nutr Res. 2011;81:245-55.

12. Custodio VI, Daneluzzi JC, Custodio RJ, Del Ciampo LA, Ferraz IS, Martinelli Jr CE, Ricco RG, Cupo P, Hering SE, Meirelles MS, Vannucchi H. Vitamin A deficiency among Brazilian school-aged children in a healthy child service. Eur J Clin Nutr. 2009;63:485-90.

13. Jingxiong J, Toschke AM, von Kries R, Koletzko B, Liangming L. Vitamin A status among children in China. Public Health Nutr. 2007;9:955.
14. Dearth-Wesley T, Wang H, Popkin BM. Under- and overnutrition dynamics in Chinese children and adults (1991-2004). Eur J Clin Nutr. 2008;62:1302-7.

15. Wei S, Ju L, Li M, Wei W. Child Health and Nutrition: Getting better and facing new challenges in China. Australas Med J. 2011:4:123-32.

16. Popkin BM, Lu B, Zhai F. Understanding the nutrition transition: measuring rapid dietary changes in transitional countries. Public Health Nutr. 2002;5: 947-53.

17. Zhai F, Wang H, Du S, He Y, Wang Z, Ge K, Popkin BM. Prospective study on nutrition transition in China. Nutr Rev. 2009:67 Suppl 1:S56-61.

18. Yu Z, Han S, Chu J, Xu Z, Zhu C, Guo X. Trends in overweight and obesity among children and adolescents in China from 1981 to 2010: a meta-analysis. PLoS One. 2012;7:e51949

19. Aasheim ET, Hofso D, Hjelmesaeth J, Birkeland Kl, Bohmer T. Vitamin status in morbidly obese patients: a cross-sectional study. Am J Clin Nutr. 2008;87: 362-9.

20. de Souza Valente da Silva L, Valeria da Veiga G, Ramalho RA. Association of serum concentrations of retinol and carotenoids with overweight in children and adolescents. Nutrition. 2007:23:392-7.

21. Mohn A, Catino M, Capanna R, Giannini C, Marcovecchio M, Chiarelli F. Increased oxidative stress in prepubertal severely obese children: effect of a dietary restriction-weight loss program. J Clin Endocrinol Metab. 2005;90:2653-8.

22. Gunanti IR, Marks GC, Al-Mamun A, Long KZ. Low serum concentrations of carotenoids and vitamin E are associated with high adiposity in MexicanAmerican children. J Nutr. 2014:144:489-95.

23. Landrier JF, Marcotorchino J, Tourniaire F. Lipophilic micronutrients and adipose tissue biology. Nutrients. 2012:4:1622-49.

\section{Submit your next manuscript to BioMed Central and we will help you at every step:}

- We accept pre-submission inquiries

- Our selector tool helps you to find the most relevant journal

- We provide round the clock customer support

- Convenient online submission

- Thorough peer review

- Inclusion in PubMed and all major indexing services

- Maximum visibility for your research

Submit your manuscript at www.biomedcentral.com/submit 